\title{
DESIGUALDADES IMPRESAS: UN PRIMER PASO PARA EL ESTUDIO DE LA HISTORIA DE LAS MUJERES EN LA ARQUEOLOGÍA PERUANA
}

\author{
PRINTED INEQUALITIES: A FIRST STEP FOR THE STUDY OF WOMEN \\ HISTORY IN PERUVIAN ARCHAEOLOGY
}

\author{
Carito Tavera Medina ${ }^{1,2}$ y Lady Santana Quispe ${ }^{1}$
}

\begin{abstract}
El presente artículo se enfoca en la situación de las mujeres al interior de la academia arqueológica peruana desde una perspectiva feminista que se caracteriza por su impulso disruptivo y crítico. En el Perú, la comunidad arqueológica se distingue por su amplitud y diversidad (a nivel de género, etnia, origen y posición socioeconómica). No obstante, son mínimas las investigaciones que han abordado la historia de las mujeres desde una visión integral. En este sentido, las autoras se plantearon la siguiente pregunta: ¿Cuál es la situación de las arqueólogas en los espacios de divulgación académica peruana? Ello, con el objetivo de estudiar el nivel de participación que tienen las arqueólogas en la producción académica local. Para tal finalidad, se han analizado dos de las revistas de mayor impacto a nivel nacional: Arqueología y Sociedad y el Boletín de Arqueología PUCP. Dicho análisis ha permitido visibilizar la inexistencia de equidad de género en estos dos espacios de divulgación científica ya que las mujeres se encuentran subrepresentadas con relación a sus pares masculinos, todo ello en contraposición al progresivo incremento de mujeres en este campo académico.
\end{abstract}

Palabras claves: arqueología peruana, arqueología feminista, análisis bibliométrico, Arqueología y Sociedad, Boletín de Arqueología PUCP.

This article focus on the topic of women in the Peruvian archaeological academy from a feminist perspective characterized by its disruptive and critical drive. In Peru, the archaeological community is distinguished by its breadth and diversity in terms of gender, ethnicity, origin, and socioeconomic position. However, research about about a comprehensive history of women in Peruvian archaeology is scarce. In this regard, and to study the level of participation that women archeologists have in local academic production, the authors raise the following question: What is the situation of women archaeologists in the Peruvian academic dissemination spaces? For this purpose, two of the journals with the highest impact at the national level, Arqueología y Sociedad and the Boletín de Arqueología PUCP, were analyzed. The analysis shows the lack of gender equality in these two spaces of scientific dissemination and the underrepresentation of women compared to their male peers, all this in contrast to the steady increase of women in this academic field.

Key words: Peruvian archaeology, feminist archaeology, bibliometric analysis, Arqueología y Sociedad, Boletín de Arqueología PUCP.

Desde la publicación en la revista Science del artículo Women in science: why so few? en la década de 1960 por Alice Rossi (1965), el cual aborda las relaciones y situación de presencia o ausencia de las mujeres en las carreras científicas, se abrió un camino para el análisis y estudio de las relaciones de género en la academia. Sin embargo, el desarrollo de esta perspectiva, como bien lo menciona Vázquez-Cupeiro (2015:80), no ha sido una tarea fácil.

La participación de las mujeres en los campos de la ciencia y la tecnología aparentemente ha experimentado y experimenta un proceso de incorporación de las mismas que va en aumento. No obstante, trabajos como el de Moss-Racusin, Dovidio, Brescoll, Graham y Handelsman (2012 citado en Agut 2016) han demostrado que las desigualdades de género siguen existiendo.

Un caso de estudio que confirma dicha situación es el trabajo desarrollado por las arqueólogas ecuatorianas Kyra Torres y Erikka Moncayo (2018) quienes analizaron el nivel de participación de las mujeres en la revista National Geographic en el intervalo de tiempo de 1988 a 1990, en comparación al periodo 2008-2010. En sus resultados, las autoras señalan que "A lo largo de los

\footnotetext{
${ }^{1}$ Université de Rennes 1, Rennes, Francia. caritotaveramedina@gmail.com; ladysantana04@ gmail.com

${ }^{2}$ Instituto Peruano de Estudios Arqueológicos, Lima, Perú.
}

Recibido: enero 2019. Aceptado: abril 2020.

http://dx.doi.org/10.4067/S0717-73562021005000301. Publicado en línea: 6-abril-2021. 
veinte años transcurridos entre la primera y la segunda muestra podemos notar que, si bien hay un avance acortando la brecha de género, hay poco o ninguno en la situación de las minorías étnicas. Aun cuando hay más mujeres publicando esto no quiere decir que existan más autoras de origen distinto al norteamericano-europeo" (Torres y Moncayo 2018:166). Cabe resaltar que este avance en la participación femenina responde a "[...] un largo y complejo proceso histórico, que aún se encuentra en constante cambio, negociación y conflicto" (Torres y Moncayo 2018:171). Y como expresa Vázquez-Cupeiro (2015), "la persistencia de la brecha de género, en países con contextos socioculturales y geopolíticos diversos, supone, además de mermar la capacidad de innovación y competitividad del sistema de ciencia y tecnología, condenar a las mujeres a permanecer aisladas" (VázquezCupeiro 2015:192).

En países como Perú, esta tendencia no es ajena al contexto global de incorporación progresiva de las mujeres en los diversos campos de la ciencia. Aunque existe un sistema de becas ${ }^{1}$ y estímulos financieros (personales) como el Premio Nacional L'ORÉAL " "Por las Mujeres en la Ciencia" impulsado por el Consejo Nacional de Ciencias y Tecnología e Innovación Tecnológica (CONCYTEC) desde el año 2008, todavía no se han implementado políticas transversales que permitan ir cambiando la situación de desigualdad y brecha de género en el campo académico y atacar problemas como "el techo de cristal"3 (González 2009). El primer escenario, la incorporación progresiva de las mujeres en la ciencia, es producto de un fenómeno que se ha venido desarrollando en Perú durante las últimas décadas, y en el que se ha podido observar un patrón de feminización universitaria. Por ejemplo, entre los años 2014 y 2016 la Superintendencia Nacional de Educación Superior Universitaria (SUNEDU en adelante) registra porcentajes que reflejan cierta paridad en relación a la presencia de mujeres y hombres matriculados en distintas universidades del país (Figura 1).

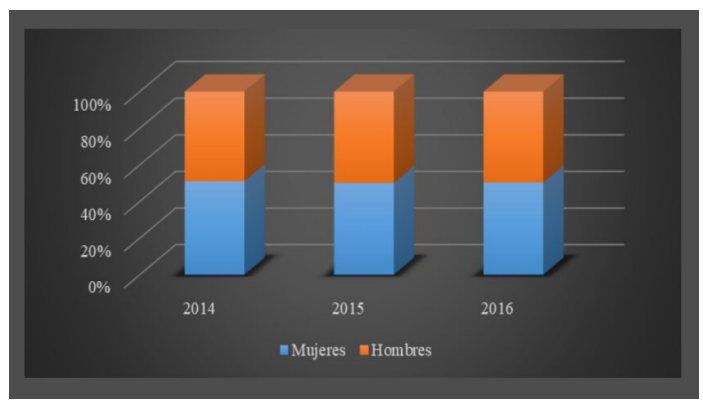

Figura 1. Porcentaje de mujeres y hombres matriculados en el sistema de educación universitaria entre los años 2014-2015. Fuente: Superintendencia Nacional de Educación del Perú.

Percentage of women and men enrolled in the university education system between 2014 and 2015. Source: Superintendencia Nacional de Educación del Perú.
En el caso específico de nuestra ciencia, el censo de "Indicadores de Educación por Departamentos" llevado a cabo por el Instituto Nacional de Estadística e Informática (INEI) en el año 2017, determinó que de toda la población universitaria a nivel nacional el $1,6 \%$ de mujeres se encontraban matriculadas en un programa de antropología o arqueología, en contraste a un $0,9 \%$ correspondiente a los varones (Interamerican Network of Academies of Science, IANAS 2018). A pesar de ello, y como se mencionó líneas arriba, cuando volcamos la mirada al mundo profesional y académico, las desigualdades entre hombres y mujeres persisten. Todo ello materializado en la disparidad salarial, el estancamiento laboral y la visibilidad de conocimiento producido por las mujeres.

Es este contexto, son escasos los esfuerzos por generar conocimiento y poner en evidencia la situación de las mujeres en el mundo académico, y en especial en la investigación en las ciencias. Uno de estos pocos, pero meritorios ejemplos, es el trabajo de investigación efectuado por el Grupo SOFIA (Alcázar y Balarín 2018; Vargas 2014) quienes develan y hacen visible las desigualdades existentes entre hombres y mujeres en el campo de las ciencias sociales. Con este panorama general preexistente, en este artículo nos enfocamos en el campo de la arqueología, el cual posee un reducido número de estudios previos.

Como muchas otras ciencias en Perú, la arqueología no cuenta con investigaciones que visibilicen en todas sus dimensiones la historia, el rol y los aportes de las mujeres. Aunque se ha realizado una exploración detallada del desarrollo histórico de la arqueología peruana, en la que se aborda el proceso de profesionalización y sus implicancias político-sociales (Tantaleán 2016; Tantaleán y Astuhuamán 2013), la historia de las mujeres y su condición en la praxis arqueológica no han sido sujetos de amplios debates ni se han brindado datos concretos sobre la naturaleza de las relaciones de género que se practican y se reproducen al interior de la comunidad.

Entre los primeros aportes que reflexionan sobre la historia de las mujeres destaca la investigación realizada por Pedro Novoa (2013). El autor desarrolla un análisis sobre la participación de Rebeca Carrión Cachot en los inicios de la arqueología. A ello se suma el trabajo de Danièle Lavallée (2013) sobre los aportes de la misión francesa, donde la autora resalta la participación activa de las mujeres en los proyectos de la misión que ella lideraba. Así mismo, es importante resaltar el segundo número de la revista "Arqueología y Vida" dedicada a la vida y obra de la arqueóloga Rosa Fung Pineda (Carrión 2008; Lavallée 2008; Pozzi-Escot 2008; Urteaga 2008). En esta misma línea, Jorge Silva (2004) realiza una semblanza 
sobre la trayectoria profesional de Fung, como parte de una compilación de escritos titulado "Quehaceres de la Arqueología Peruana” publicada por el Museo de Arqueología y Antropología de la Universidad Nacional Mayor de San Marcos.

Esta situación y reflexiones iniciales ponen en evidencia una parte de la realidad de la arqueología peruana: aquella en la que se ha generado un proceso de invisibilización de la presencia y aportes generados por las mujeres en este campo. Sin embargo, estas primeras lecturas críticas sobre la historia de esta ciencia sitúan su práctica en el presente, proporcionan herramientas y dan un marco para el desarrollo de nuevas perspectivas en la lectura de la trayectoria de la arqueología en el Perú (Díaz-Andreu 2013; Patterson 2013).

Estas nuevas lecturas, consideramos, pueden ser realizadas desde las perspectivas que otorgan la Arqueología Feminista. Tal aproximación ha buscado cambiar la manera de practicar la arqueología a nivel epistemológico, generando una autocrítica a nuestro androcentrismo académico e invitándonos a reconfigurar las dinámicas internas de la praxis arqueológica (Berrocal 2009; Gero y Conkey 1991). En realidad, se tratan de dos formas de evaluar las relaciones de género en la arqueología. La primera vinculada al criterio epistemológico desde el cual se evalúa la producción y construcción del conocimiento científico con relación a las mujeres del pasado, y la segunda, con cómo estas categorías formuladas se reflejan en la práctica científica (Bellelli et al. 1993).

Estas condiciones permiten adentrarnos en una de las tantas líneas de investigación que quedan pendientes o por desarrollar a partir de los primeros aportes mencionados, y de las perspectivas que ofrecen la Arqueología Feminista y la Arqueología de Género. Una de ellas, y motivo de este trabajo, es la participación de las mujeres en los espacios de difusión académica en Perú dentro del marco de las relaciones de género al interior de la academia arqueológica.

Desde las corrientes teórico-metodológicas mencionadas, las distintas comunidades arqueológicas de Latinoamérica han buscado incorporar dichas perspectivas como herramienta para abordar temas vinculados con las relaciones de género en la praxis arqueológica. En esta investigación se ha logrado tener acceso a estudios análogos desarrollados en los países de Argentina, Ecuador y Perú.

En el caso de Argentina, Cristina Bellelli, Mónica Berón y Vivian Scheinsohn en el año 1993 realizaron un análisis de la práctica arqueológica en este país. Las investigadoras proponen una vía de estudio del sistema sexo/género desde el ejercicio profesional y no desde la producción del conocimiento (Bellelli et al. 1993:48). $\mathrm{Si}$ bien los datos que presentan indican una alta representación numérica de mujeres, consideran que no reflejan verdaderamente cuántas de ellas acceden a las jerarquías superiores y participan de las esferas del poder en la disciplina. Finalmente, concluyen que "[...] al predominar los hombres en las instancias superiores de la carrera profesional, son ellos los que deciden quiénes investigan, qué se investiga y a quiénes se les darán subsidios" (Bellelli et al. 1993:53).

Una situación no tan lejana es la que describen las arqueólogas ecuatorianas, Victoria Domínguez Sandoval, Josefina Vásquez Pazmiño y María Auxiliadora Cordero (2018:7) quienes señalan que "[...] aunque un sinnúmero de investigaciones arqueológicas se ha[n] llevado a cabo con la participación de mujeres, la presentación y la publicación de los resultados siguen estando mayoritariamente monopolizadas por voces masculinas, lo que ha causado cierta invisibilidad del trabajo femenino en la arqueología". Torres y Moncayp (2018), confirman esta situación por medio del análisis bibliométrico de la revista National Geographic y entrevistas anónimas sobre el rol de las mujeres en la arqueología ecuatoriana, señalando que la práctica arqueológica en Ecuador, desde sus orígenes "fue considerada una profesión masculina, imaginario del cual aún quedan fuertes rezagos" (Torres y Moncayo 2018:171).

En lo que respecta a Perú, la producción académica reporta la existencia de un ambiente altamente machista y sexista (Arroyo 2019:300; Cabrera 2019:284), donde la violencia de género es una práctica existente, la cual se da en "[...] un marco de desigualdad y opresión de género, que, más allá de brindar los espacios de apoyo y acompañamiento a las víctimas, tiende a revictimizar a la persona y hacerla presa de sus miedos" (Tavera 2019:257).

Asimismo, Gianella Pacheco (2019) sostiene que las condiciones socioeconómicas se convierten en un limitante para la culminación de la carrera tanto para hombres como para mujeres. Pero como esta arqueóloga peruana señala: “[...] las chicas que ingresaron conmigo dejaban la carrera porque un embarazo no planificado se interponía. Muchas no habían tenido acceso a una buena educación sexual y no sabían cómo cuidarse de manera efectiva [...]" (Pacheco 2019:308). De esta manera, la autora añade nuevos factores de desigualdad a los que están expuestas las mujeres desde sus primeros años de formación universitaria.

Finalmente, a estos estudios, se suma el realizado por Santana (2019). Esta autora analiza la práctica profesional y académica al interior de la arqueología peruana a través de un estudio cuantitativo-comparativo del número de ingresantes, matriculados y egresados de la carrera de arqueología a nivel nacional, además de la presencia de arqueólogas en las planas docentes universitarias y la participación de las mismas en espacios académicos como el Congreso Nacional de 
Arqueología. Los resultados ponen en evidencia la presencia de los llamados techos de cristal, nichos académicos, desigualdad y subrepresentación de las mujeres en este campo (Santana 2019:278).

Contemplando la problemática expuesta, este estudio propone abordar, de forma sistemática, el estado de las mujeres al interior de la academia arqueológica peruana. Para ello, se planteó la siguiente interrogante: (1) ¿Cuál es la situación de las mujeres en los espacios de divulgación académica peruana? Así mismo, y para poder abarcar los matices que pueden generar tal estudio, se formularon las siguientes preguntas complementarias: (2) ¿Cuántas son las mujeres que publican en las revistas locales de arqueología?, (3) ¿cuál es el orden que ocupan en las publicaciones co-autoradas? y (4) ¿cuáles son sus filiaciones institucionales? El presente artículo busca abrir un camino para el desarrollo de estudios desde la perspectiva de la arqueología feminista y contribuir en la construcción de la historia de las mujeres al interior de la arqueología peruana. Se aborda este objetivo desde el "sistema sexo-género" y se recurre a un análisis bibliométrico de dos de las revistas de mayor continuidad e impacto: Arqueología y Sociedad, publicada por el Museo de Arqueología y Antropología de la Universidad Nacional Mayor de San Marcos (AS UNMSM) y el Boletín de Arqueología PUCP, de la Pontificia Universidad Católica del Perú (BA PUCP).

Asimismo, este trabajo realza la situación que viven las arqueólogas, siendo un instrumento de cuestionamiento del estado actual de la academia en su conformación y contenido. Así, este estudio se convierte en una herramienta útil para iniciar el análisis de la historia de las arqueólogas en el Perú, la cual, si bien reconoce y premia a alguna de ellas -aquellas "singulares"- paradójicamente termina siendo un medio para ocultar un gran número de profesionales.

\section{Metodología}

Como hemos señalado, el análisis bibliométrico se ha realizado a partir de las revistas $A S$ UNMSM y $B A$ $P U C P$, las cuales poseen el mayor factor de impacto debido a su continuidad, citas realizadas por la comunidad arqueológica y porque ambas constituyen algunos de los pocos espacios donde los trabajos de investigación son publicados en lengua hispana y de libre acceso.

La muestra analizada comprende 32 números con un total de 349 artículos publicados por $A S$ UNMSM entre 1970 y 2016, aunque en dicho intervalo de tiempo se registran años en el que no se publicó ningún número de la revista. Mientras que para el BA-PUCP se analizaron 23 números que contienen 359 artículos publicados de manera continua entre 1997 y 2017. Esta información referente a los años permitió analizar la tendencia de la participación femenina a lo largo de la historia de ambos espacios de difusión académica.

Con respecto al desarrollo metodológico, hemos descargado los 23 números del BA PUCP de la página web: http://revistas.pucp.edu.pe/index.php/ boletindearqueologia/issue/archive. En tanto que los 32 números de la $A S$ UNMSM se hallan en el siguiente reposito virtual: http://revistasinvestigacion.unmsm.edu. pe/index.php/Arqueo/issue/archive. De esta manera, se ha sistematizado el número de artículos por analizar. Las bases de datos, en ambos casos, proporcionan la firma, con los nombres completos de cada autor y autora, lo cual nos ha facilitado identificar su sexo.

Una vez identificados los artículos firmados por mujeres y hombres, se procedió a la definición de cinco categorías básicas: (1) autoría exclusiva femenina, (2) autoría exclusiva masculina, (3) co-autoría entre autores masculinos, (4) co-autoría entre autoras femeninas y (5) co-autoría mixta.

Asimismo, se consideró necesario analizar el orden en el que aparecen las mujeres que forman parte de publicaciones de co-autoría mixta con pares masculinos, teniendo en cuenta la primera, segunda y hasta la tercera posición. La importancia de considerar este orden radica en la forma de evaluación de los expedientes académicos en un sistema de postulación basado en la meritocracia.

Adicionalmente, este análisis bibliométrico generó categorías para el estudio de la procedencia institucional de las mujeres que participaron en los artículos por medio de autorías exclusivas femeninas, co-autorías femeninas y co-autorías mixtas. Esto nos permitió evaluar el grado de posibilidades que generan las instituciones a las cuales pertenecen o de las cuales formaron parte como estudiantes. Para lo anterior, también se consideró si las autoras eran de origen peruano o de otra nacionalidad. Así mismo, a aquellas de origen peruano, se les disoció a partir del tipo de institución de educación superior en la que cursaron estudios de pre-grado. De esta forma, fueron separadas en las categorías de universidad: (a) pública y, (b) privada.

Finalmente, si bien se ha argumentado previamente cuáles fueron los motivos de elección de estas dos revistas, consideramos que un análisis estadístico de ambas caracterizan una parte de lo que podría ser el total de la producción académica en el campo de la arqueología peruana, tomando en cuenta que las publicaciones relacionadas con el estudio de las sociedades del pasado de los Andes Centrales no solo se restringe a las arqueólogas nacionales, sino que está nutrido por el aporte de colegas extranjeras. Esto nos remite a espacios de divulgación internacional, en los cuales algunas arqueólogas nacionales tienen acceso.

A continuación, se presentan los datos obtenidos del análisis estadístico aplicado a las revistas Arqueología y Sociedad y al Boletín de Arqueología PUCP. 


\section{Resultados}

Los datos obtenidos como resultado del análisis bibliométrico han sido subdivididos en tres temas que abarcan:

1. Producción científica: corresponde a las cantidades de participantes en cada número y sus porcentajes.

2. La cuantificación de nuestra presencia: se refiere a los datos de las categorías principales planteadas.

3. ¿Quiénes son y de dónde vienen?: en este punto se exponen los resultados de la filiación institucional y tipo de institución de formación.

\section{Producción científica}

Debemos indicar que el número de firmas es diferente del número de autores o personas que publican, puesto que es recurrente para ambas revistas que cada autor o autora pueda intervenir o publicar en más de un trabajo en un mismo número y año, o en distinto número y año (Agut 2016). La Tabla 1 muestra los datos de autores y firmas.

Durante el período 1970-2016 se publicaron en AS UNMSM 349 artículos en los que participaron 489 autoras/es. A partir de este dato, obtuvimos un total de mujeres (77) y hombres (238) que suponen el 24,0\% y $76,0 \%$ respectivamente (Tabla 1, Figura 2).

Para el caso de BA PUCP, entre los años 19972017 esta revista publicó 359 artículos en los que participaron 386 autoras/es. Del mismo modo, a partir de estos datos, obtuvimos el total de autoría femenina (121) y autoría masculina (265) que corresponden al $31 \%$ y $69 \%$ respectivamente (Tabla 1, Figura 2).

Las Figuras 3 y 4 muestran la tendencia de la participación de mujeres y hombres en cada uno de los números publicados.

En $A S$ UNMSM la cantidad de firmas por año o edición, generó dos líneas de tendencia para investigadores e investigadoras (Figura 3). En ellas se observa que al inicio de la revista, en el año 1970, se contó con un número mínimo (1) de firmas masculinas y nula (0) existencia de firmas femeninas, lo cual se ve reflejado en la cantidad de participantes: una sola persona contabilizada. A lo largo del tiempo el número de firmas masculinas fue en aumento, experimentando su pico más alto en el año 2013 con un total de 31 firmas. Un proceso diferente experimenta la línea de firmas femeninas que no fue aumentando constantemente entre los años 1970 y 1984. Por el contrario, la presencia de firmas femeninas se reduce a cuatro para un total de nueve números. Sin embargo, ocurre algo interesante en el número 6 del año 1971 en el cual la única firma existente, pertenece a una mujer.

A través del tiempo ambas líneas no experimentan picos de ascendencia y descendencia drásticas, sino hasta 2012 cuando el número de firmas masculinas se empiezan a multiplicar de cinco o hasta seis veces con

Tabla 1. Número de artículos por revista. Número y porcentaje de autorías de mujeres y hombres en AS-UNMSM y BA-PUCP respectivamente.

Total number of articles per journal. Number and percentage of authorships of women and men in $A S-U N M S M$ and $B A-P U C P$ respectively.

\begin{tabular}{cccccccc}
\hline Revista & Artículos & Firmas & Autorias & Autoría Femenina & $\%$ & Autoría Masculina & $\%$ \\
\hline AS-UNMSM & 349 & 489 & 315 & 77 & 22 & 238 & 78 \\
\hline BA-PUCP & 359 & 503 & 386 & 121 & 31 & 265 & 69 \\
\hline
\end{tabular}

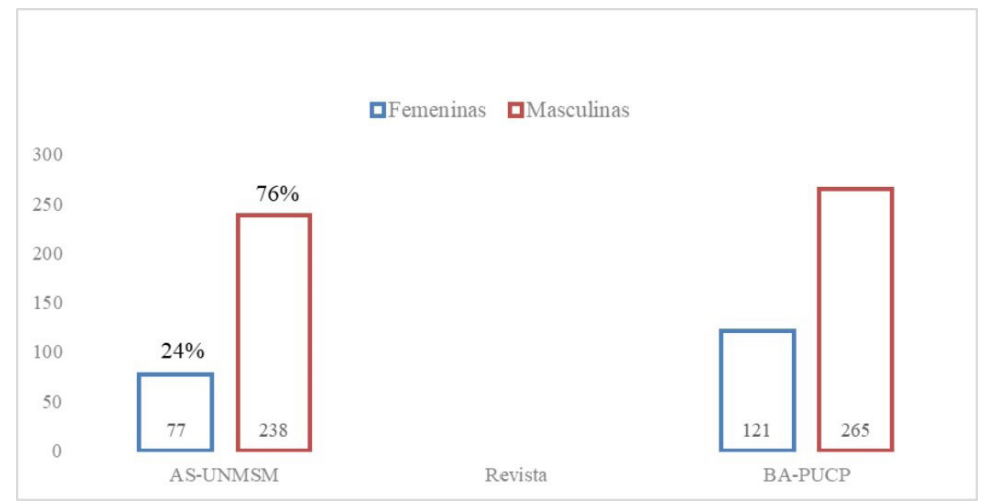

Figura 2. Mujeres y hombres que publicaron en el AS-UNMSM (1971-2016) y BA-PUCP (1997-2017).

Women and Men who have published in AS-UNMSM (1971-2016) and BA-PUCP (1997-2017). 


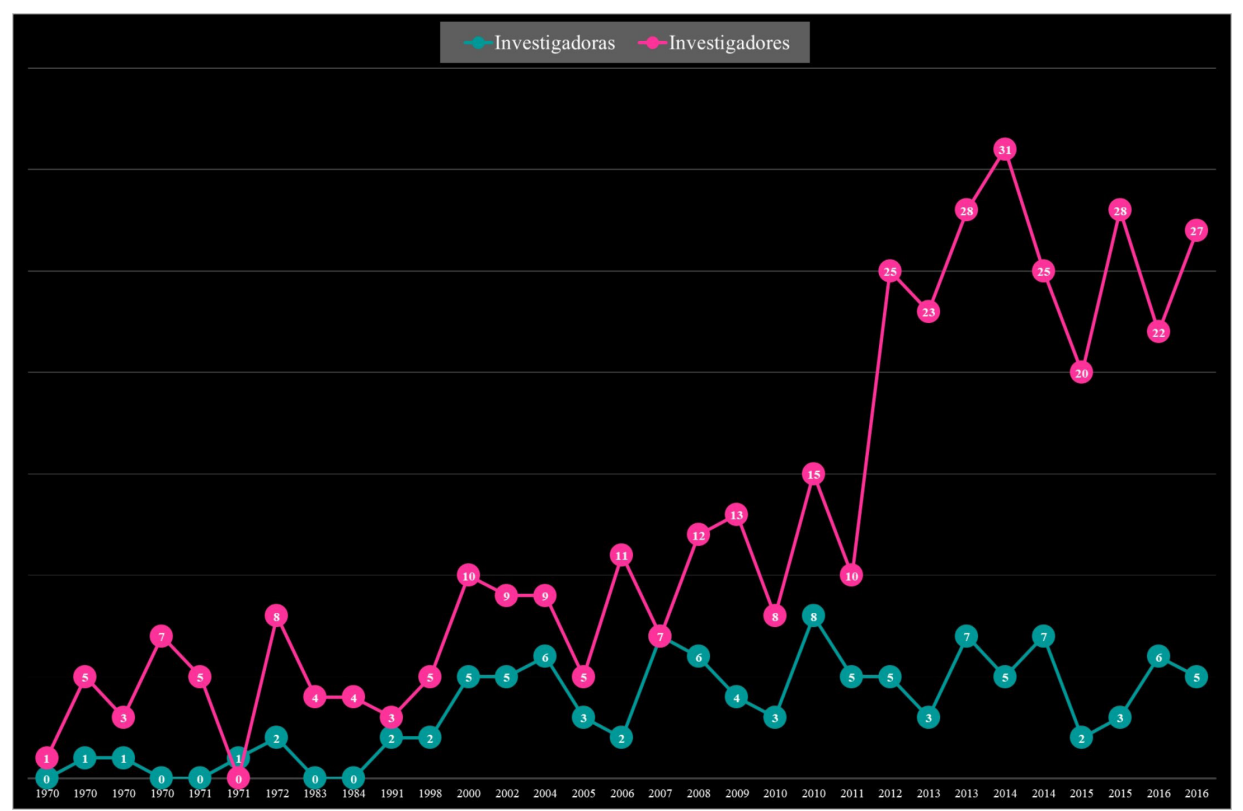

Figura 3. Tendencia de la participación de mujeres y hombres en la revista AS-UNMSM.

Participation trend of women and men in the AS-UNMSM journal.

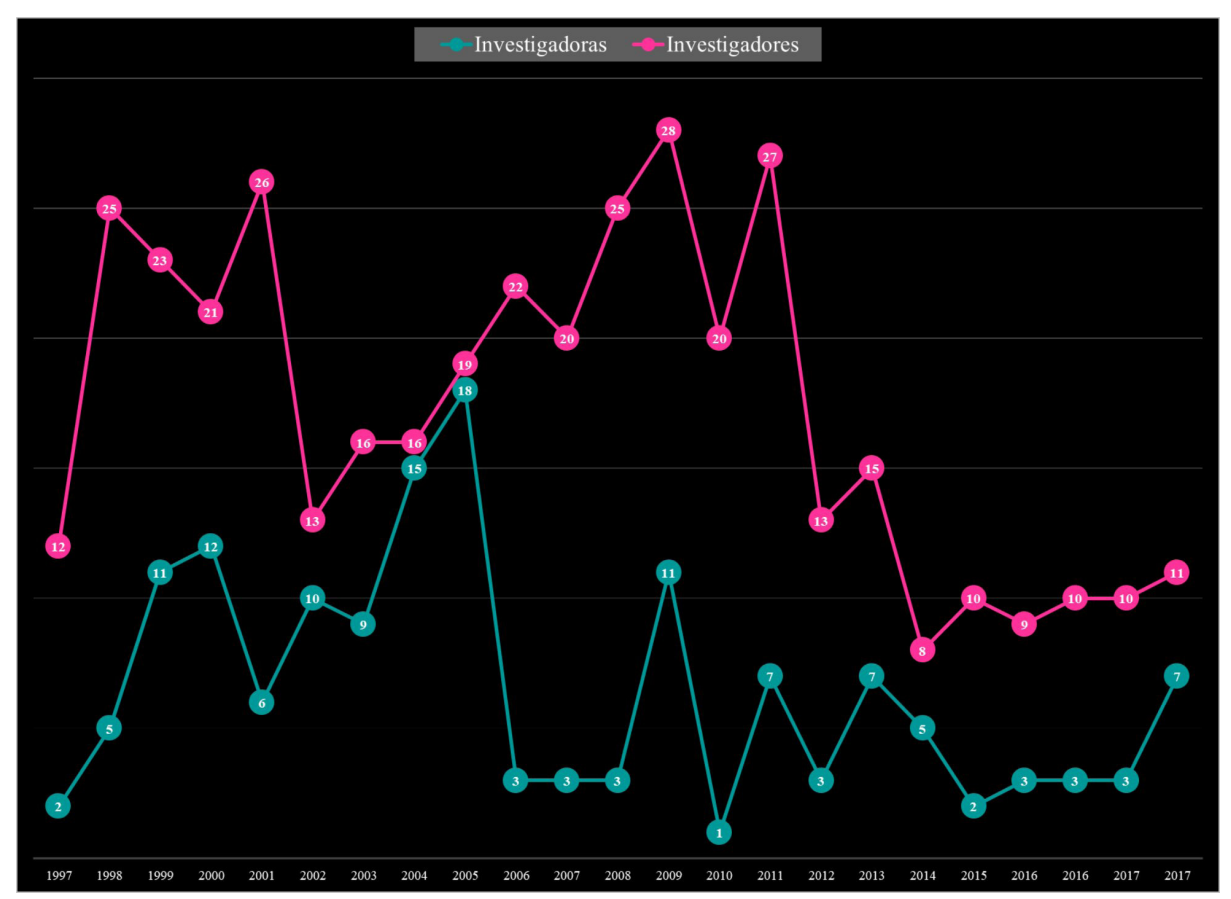

Figura 4. Tendencia de la participación de mujeres y hombres en la revista BA-PUCP.

Participation trend of women and men in the BA-PUCP journal. 
relación a la cantidad de firmas femeninas. Esta tendencia ha generado una brecha dramáticamente amplia que va en contradicción con el actual aumento de arqueólogas en el Perú 5 . Este proceso ha sido constante hasta el último número publicado en el 2016 (el 32).

En el BA PUCP (Figura 4), del mismo modo que en la revista $A S$ UNSMS, las cantidades de firmas femeninas y masculinas han generado dos líneas de tendencia que revelan la presencia de investigadoras e investigadores por cada año o número publicado. El inicio del boletín refleja la existencia de un número considerable de firmas masculinas (12) frente a un número mínimo de firmas femeninas (2). Por su parte, las firmas masculinas han experimentado un aumento constante adquiriendo un pico máximo de 28 firmas en el año 2009, aunque disminuyen drásticamente en el año 2012. De hecho, es en el 2014 cuando esta disminución se torna constante.

La línea de firmas femeninas a través del tiempo fue en aumento e, incluso, experimentó un pico de superioridad con relación a las firmas masculinas en el año 2005 (con 18 firmas frente a 10 firmas masculinas). No obstante, esta tendencia se desacelera drásticamente en ese mismo año. Después de ello, la cantidad de firmas femeninas solo ha tenido contados momentos de incremento, como el ocurrido en el 2009 o 2011.

En el tiempo, ambas líneas han desarrollado procesos de cambio que generaron dos momentos en el que se produce una amplia brecha de desigualdad entre las firmas masculinas y femeninas. El primero ocurre en el inicio de ambas revistas, desde el año 1997 hasta el 2001. Después de ello, el segundo momento, y el más notorio y drástico, ocurre entre los años 2006 y 2011. Actualmente la cantidad de firmas femeninas y masculinas están produciendo una reducción de esta brecha y se están generando cambios importantes.

\section{Cuantificación de nuestra presencia}

Con relación a las categorías planteadas a partir de la autoría, obtuvimos que en AS UNMSM del total de artículos (349), los de autoría exclusivamente femenina corresponden a 45 y representan el $13 \%$. Mientras que las autorías exclusivamente masculinas ascienden a 208 artículos, que comprende el 59\% del total. En la categoría de co-autoría masculina se obtuvo la cantidad de 44 trabajos, correspondientes al 14\% del conjunto de publicaciones. En cuanto a las co-autorías femeninas se logró identificar un total de tres artículos que representan el $1 \%$. Finalmente, la categoría de co-autoría mixta suma un total de 45 publicaciones que comprenden al 13\% del conjunto analizado (Figura 5).

En el BA PUCP, del total de 359 artículos, las co-autorías femeninas se encuentran en 57 de los artículos. Mientras que los que corresponden a autoría exclusivamente masculina ascienden a un total de 188 . A esto se suman los de co-autoría mixta que suman un total de 52. Asimismo, los artículos de co-autoría masculina muestran un total de 53. Finalmente, las producidas en co-autoría de investigadoras suman un total de nueve escritos.

De esta forma, se colige que, del cien por ciento de publicaciones, el 52\% de ellas responden a hombres, frente a un reducido $16 \%$ que representa las publicaciones hechas exclusivamente por autoras femeninas. A ello, se agrega

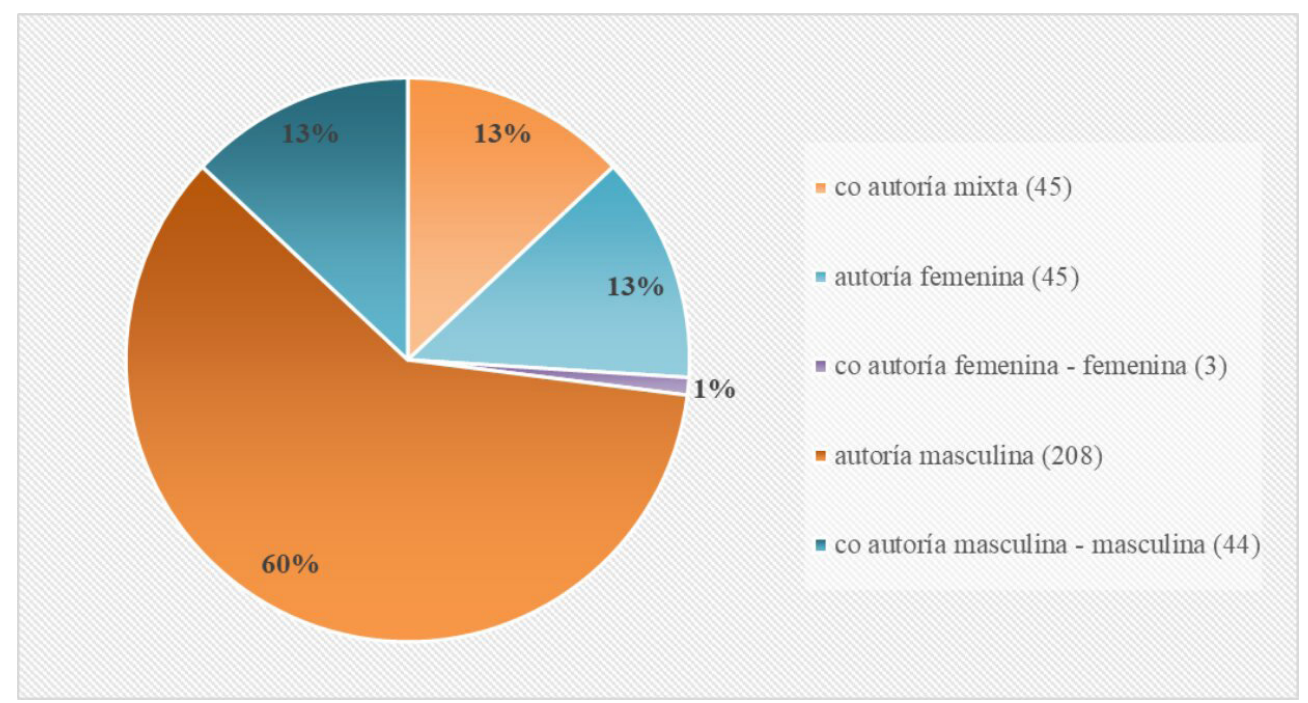

Figura 5. Análisis del número de publicaciones realizadas en AS-UNSM a partir al tipo de autoría. Analysis of the number of publications in AS-UNSM based on authorship type. 
un $15 \%$ de publicaciones de co-autoría masculina ante un ínfimo 3\% de co-autoría de investigadoras femeninas. Finalmente, observamos un $14 \%$ de publicaciones de co-autoría mixta (Figura 6).

En cuanto a la colaboración de investigadores que caen en la categoría co-autoría mixta, revela que en $A S$ UNMSM y BA PUCP, los porcentajes de colaboración entre autorías femeninas y masculinas se encuentran entre el $13 \%$ y $14 \%$ respectivamente. Esta asimetría en lo que se refiere a las publicaciones de co-autorías masculinas es lógica debido a la menor existencia tanto de firmas como de autorías.

En esta sub-muestra también se ha calculado el orden en la que aparecen las autorías femeninas. Este cálculo se ha realizado considerando el total de las firmas registradas en la categoría co-autoría.

El análisis revela que, de un total de 114 firmas en AS UNMSM, las mujeres que se ubican como primeras autoras corresponden a algo más de la mitad (13\%) del porcentaje de los investigadores masculinos (25\%). Las que se ubican como segundas autoras se encuentran en una relación más equilibrada con respecto a las autorías masculinas que se hallan en esta posición, siendo el $12 \%$ y $16 \%$ del total de firmas respectivamente. En la tercera autoría, las mujeres representan un $7 \%$ mientras que los investigadores masculinos alcanzan el $10 \%$. Finalmente, encontramos las otras posiciones en las cuales las investigadoras figuran con un $9 \%$ y los investigadores con el $8 \%$ del total mostrando que, en este caso, son las mujeres las que suman un mayor porcentaje. Sin embargo, son las que se encuentran desde la cuarta posición en adelante (Figura 7).
En el BA PUCP se registró un total de 182 firmas, en las cuales las mujeres que se ubican como primeras autoras corresponde al 7,69\% frente al $20,87 \%$ de investigadores masculinos. Las autorías femeninas que se encuentran en segunda posición corresponden al $13,73 \%$, mostrando cierta equidad con sus pares masculinos que conforman el 14,28\% del total de firmas respectivamente. En la tercera autoría, las mujeres representan un $8,24 \%$ mientras que los investigadores masculinos alcanzan el 7,14\%, reflejando una relación casi equitativa entre ambos. Finalmente, encontramos las otras posiciones en las cuales las investigadoras figuran con un $11,53 \%$ y los investigadores con el $16,48 \%$ del total (Figura 8).

\section{¿Quiénes son y de dónde vienen?}

Este último apartado, aunque difiere parcialmente de los anteriores, buscó reflejar en términos porcentuales cuáles son los países de formación de las investigadoras que publicaron en ambas revistas. En el caso de las arqueólogas peruanas, se refiere a las instituciones a las que estaban afiliadas durante su investigación, así como las universidades en las cuales desarrollaron su formación de pregrado. Estas características nos permitirán discutir más adelante algunos aspectos, como las posibilidades y accesos en medios de difusión científica.

Con relación a este aspecto, se observó que, de un total de 77 investigadoras, la revista $A S$ UNMSM cuenta con la participación de 52 autoras peruanas, que representan el $66 \%$, seguido de investigadoras

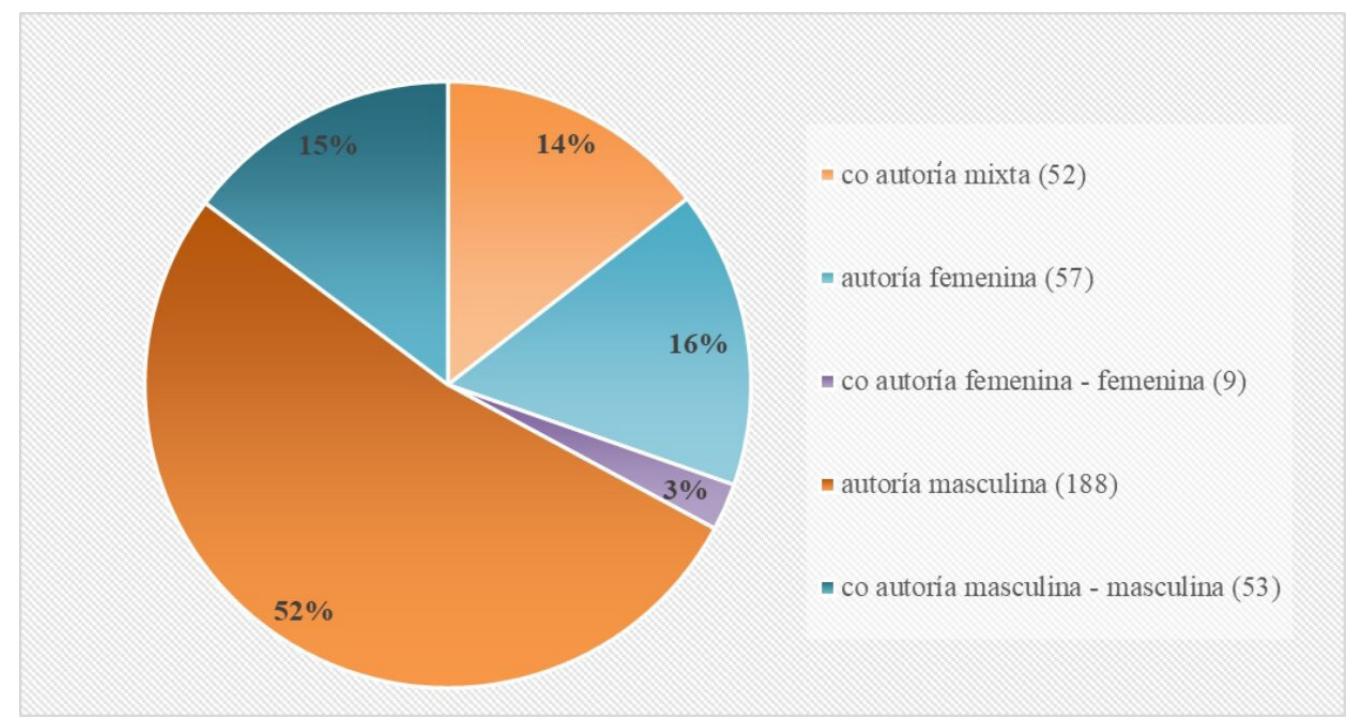

Figura 6. Análisis del número de publicaciones realizadas en BA-PUCP a partir al tipo de autoría.

Analysis of the number of publications in BA-PUCP based on authorship type. 


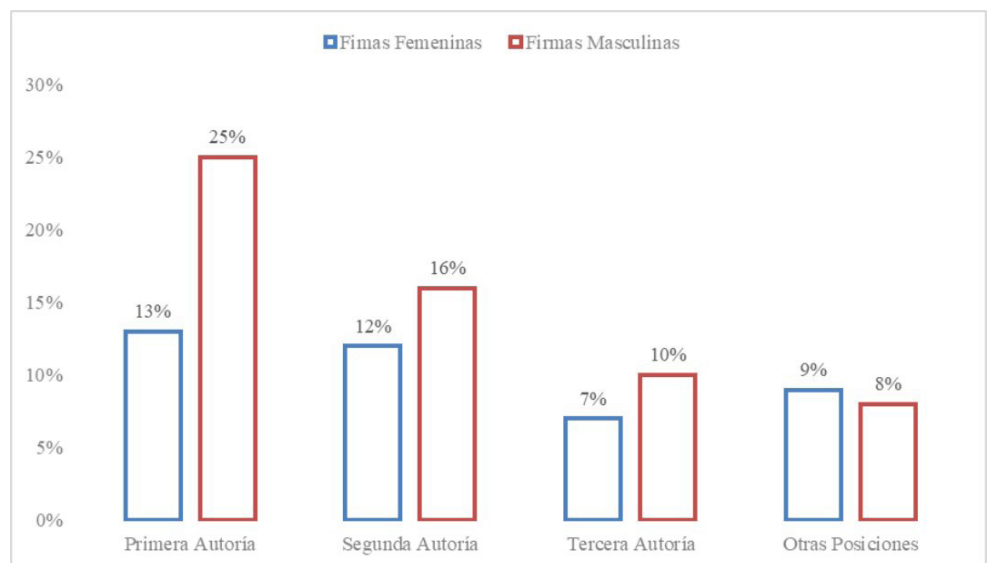

Figura 7. Porcentajes de mujeres y hombres de acuerdo a la posición en la que firman los artículos en la revista de AS-UNMSM.

Percentages of women and men according to the position in which they sign the articles in the AS-UNMSM journal.

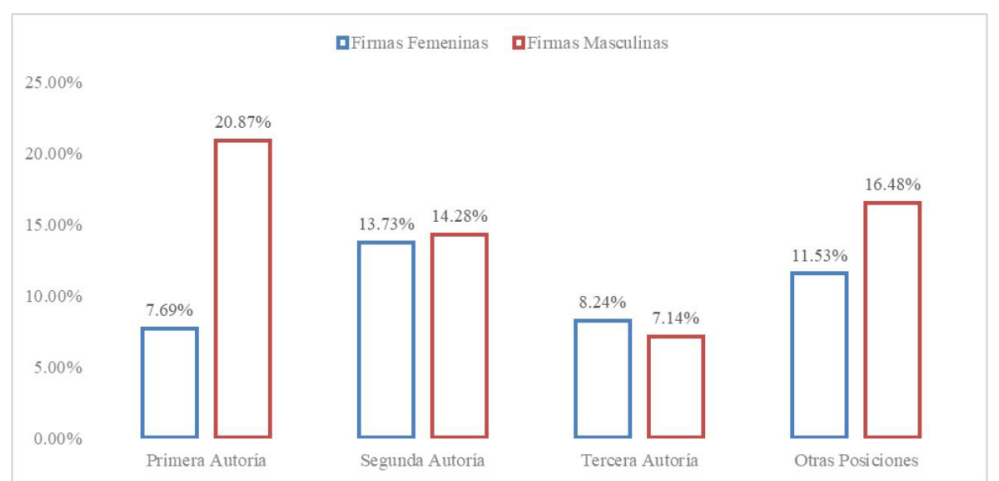

Figura 8. Porcentajes de mujeres y hombres de acuerdo a la posición en la que firman los artículos en el BA-PUCP.

Percentages of women and men according to the position in which they sign the articles in the BA-PUCP.

de los Estados Unidos con 11 participantes que constituyen el 14\%. A continuación se encuentran las investigadoras de Alemania y de Argentina con tres participaciones (4\% y 4\% respectivamente); Canadá y Francia con dos participantes por cada país (3\% y $3 \%$ ); A continuación, tenemos presencia femenina de Colombia, Chile y España con 1 participación por cada uno de los países (1\% en los tres casos). Finalmente, se generó el campo "No Identificado" debido a que no se pudo reconocer el país de formación (Figura 9).

Del análisis de todos los números publicados por el $B A P U C P$, en primerlugar, contamos conlaparticipación de investigadoras provenientes de Estados Unidos, con un total de 22 autoras que representa el $42 \%$ del total de participantes femeninas. Esto va seguido por 18 autoras de Perú, que representan, el 35\% del total. A continuación se encuentran Argentina representada por seis autoras que conforman el $11 \%$ del total; Francia con tres investigadoras que corresponden al $6 \%$ del total; y finalmente Chile, China y Dinamarca, cada uno con una representante con el $2 \%$ respectivamente (Figura 10).

Con respecto a las autoras de origen peruano identificamos que a partir de su centro de formación profesional a nivel de pre-grado, la participación de las arqueólogas provenientes de universidades públicas en la revista $A S$ UNMSM es del 82,69\%, mientras que las de universidades privadas (en el caso de Perú solo la PUCP) es del 13,46\%. Habiendo registrado un 3,84\% que no se pudo determinar en qué institución estudiaron el pregrado (Figura 11).

En este mismo sentido, el porcentaje de universidades nacionales se encuentra distribuido entre la Universidad Nacional Mayor de San Marcos (UNMSM) con un 57,69\%, la Universidad Nacional San Luis Gonzaga de Ica (UNICA) representada por 


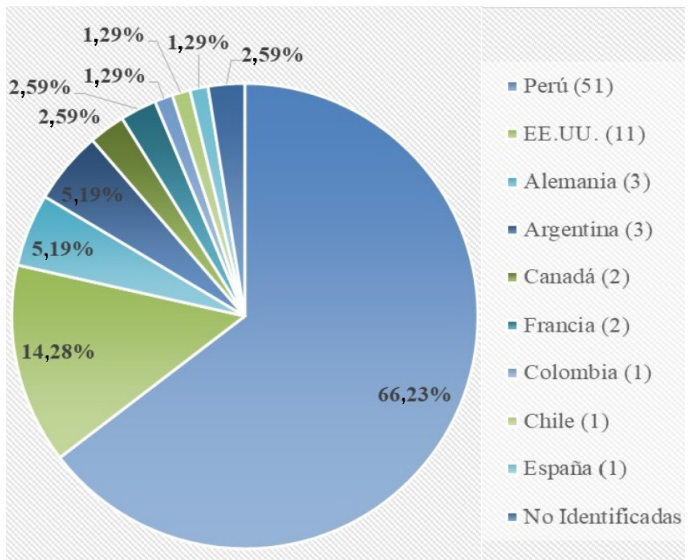

Figura 9. Procedencia de las arqueólogas que publicaron en AS-UNMSM.

Nationality of women archaeologists who have published in AS-UNMSM.

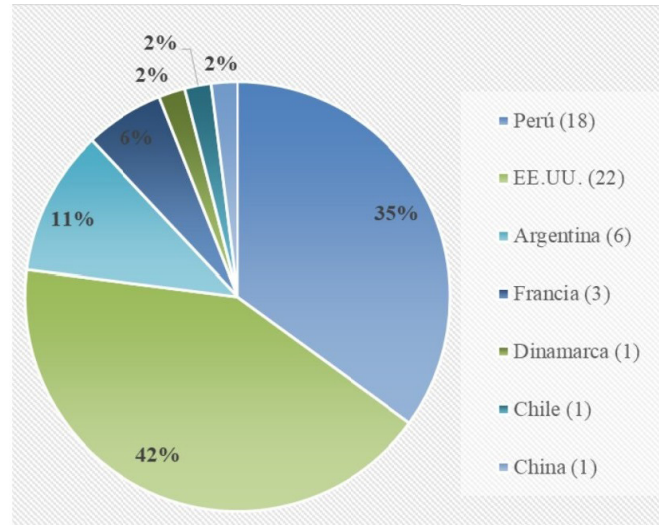

Figura 10. Procedencia de las arqueólogas que publicaron en BA-PUCP.

Nationality of women archaeologists who have published in BA-PUCP.

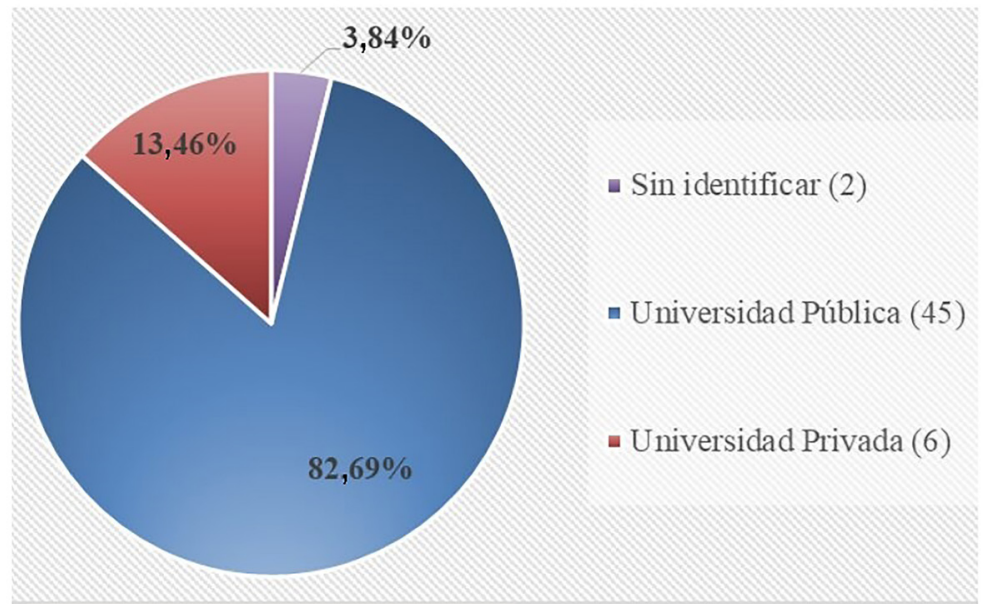

Figura 11. Porcentaje de autoras procedentes de universidades públicas y privadas que han publicado en AS-UNMSM.

Percentage of women authors from public and private universities who have published in AS-UNMSM. 
el 7,69\%, la Universidad Nacional Federico Villareal (UNFV) con un $5,76 \%$, y la Universidad Nacional de Trujillo (UNT), la Universidad Nacional San Antonio de Abad del Cusco (UNSAAC) y la Universidad Nacional San Cristóbal de Huamanga (UNSCH) con 3,84\% cada una. A todo ello se suma el $13,46 \%$ representado por la Pontificia Universidad Católica del Perú (PUCP) (Figura 12).

Con respecto al BA-PUCP, al analizar la casa de estudio donde las autoras realizaron su formación de pregrado, se evidencia que el $55,55 \%$ corresponde a la Pontificia Universidad Católica del Perú. Las autoras que provienen de universidades públicas son ocho, las mismas que se distribuyen del siguiente modo; UNMSM (5), UNT (2) y UNSAAC (1), y representan el $27,7 \%, 11,11 \%$ y $5,55 \%$ respectivamente (Figura 13 ). Finalmente, podemos observar que los gráficos reflejan una proporción casi equitativa de la participación de mujeres provenientes de universidades públicas como privadas, representadas cada una por el $44 \%$ y $56 \%$ respectivamente (Figura 14).

\section{Discusión}

En este artículo se han revisado y analizado un total de 708 trabajos científicos publicados en dos de las

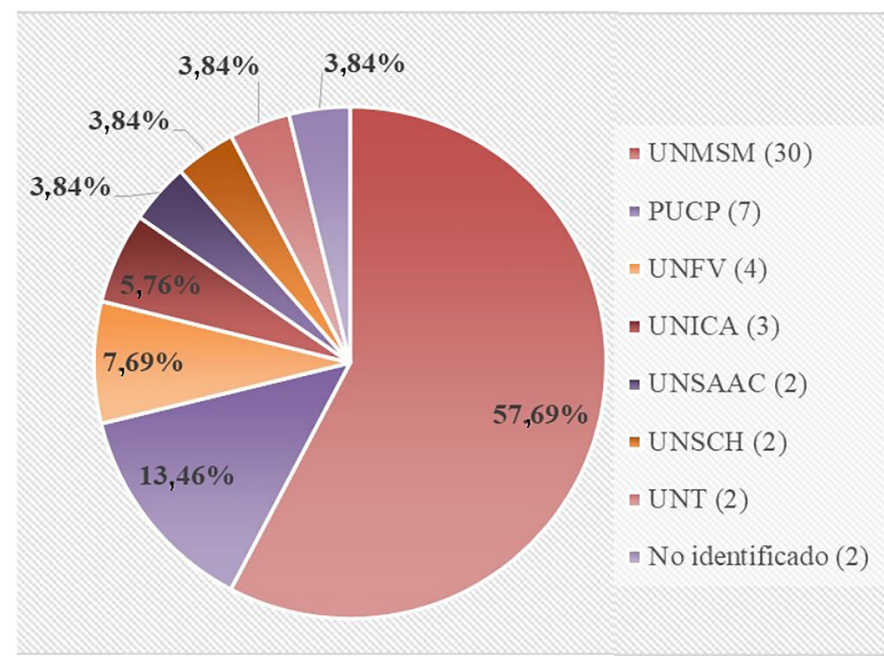

Figura 12. Universidades peruanas donde estudiaron su pregrado las arqueólogas que publicaron en AS-UNMSM.

Peruvian universities where women archaeologists who have published in ASUNMSM obtained their undergraduate degree.

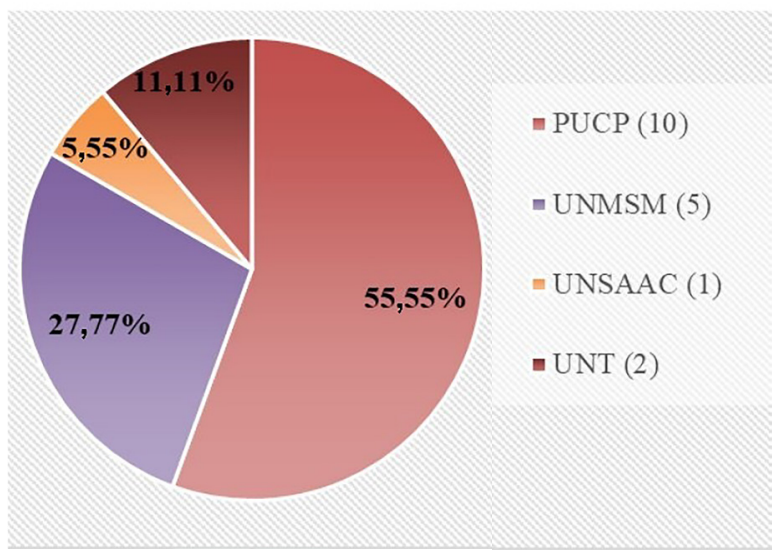

Figura 13. Universidades peruanas donde estudiaron su pregrado las arqueólogas que publicaron en el BA-PUCP.

Peruvian universities where women archaeologists who have published in BA-PUCP obtained their undergraduate degree. 


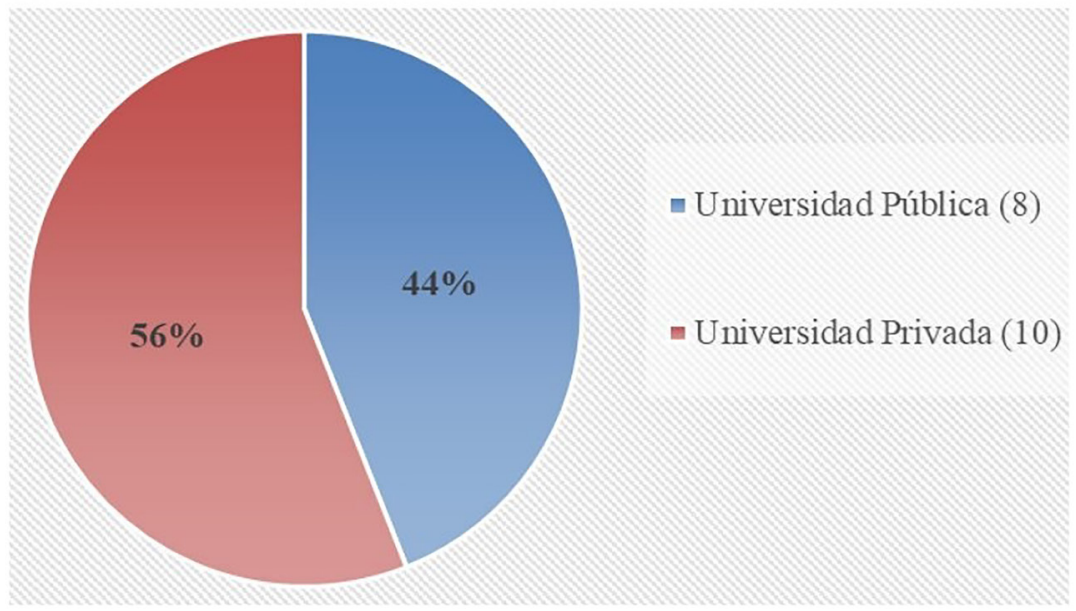

Figura 14. Porcentaje de autoras procedentes de universidades públicas y privadas que han publicado en BA-PUCP.

Percentage of women authors from public and private universities who have published in BA-PUCP.

revistas de mayor impacto y continuidad en el campo de la arqueología peruana: $A S$ UNMSM (349) y BA PUCP (359). Se observa que en ambas revistas la cantidad de autoras (198) se encuentra por debajo de la mitad del número de autores (508). Sobre esta misma línea, las firmas que corresponden a investigadoras femeninas alcanzan solo 255 casos considerando las dos revistas, en contraste a las 737 firmas masculinas que representan el triple de las firmas de autoría femenina.

Es clara la subrepresentación de investigadoras femeninas en esta parte del análisis, y tiene lógica correlacional si tomamos en cuenta la participación real (autoría-individuo) de las mujeres (Tabla 1). Este panorama se desdibuja, también, si centramos nuestra atención en dos publicaciones que desarrollan el proceso histórico de la arqueología peruana, que muestra la escasa presencia de mujeres tanto en el contenido en forma de artículos como su presencia en citas a lo largo de los distintos aportes vertidos (Tantaleán y Astuhuamán 2013). Esta situación forma parte de la tendencia mundial registrada por Larivière et al. (2013), quienes sostienen que las mujeres representan menos del $30 \%$ de la producción científica general. Esta situación aún no ha sido analizada ni explicada ampliamente en la arqueología. Sin embargo, consideramos que tiene relación con factores socioculturales como la carga familiar y acceso a recursos, y con factores de índole laboral como la dedicación exclusiva a la docencia y cierto tipo de trabajo que limita el desarrollo académico (Alcázar y Balarín 2018). A todo lo anteriormente expuesto sumamos la falta de políticas de igualdad de género que fomenten la incorporación de mujeres en el mundo académico y la escasez de referentes femeninos que brinden la imagen de tutoras para las arqueólogas en formación.

Además, la tendencia de participación de investigadoras por firma muestra números llamativos. Primero, aunque la presencia de autorías femeninas no varía en cantidad, esta tiende a ser, en promedio, menos de la mitad en comparación con sus pares masculinos. Segundo, existen rangos de años en el que la brecha entre firmas femeninas y masculinas se amplía drásticamente. Por ejemplo, entre el 2011 y 2016 en la revista ASUNMSM las proporciones entre investigadoras e investigadores llegó a ser de la décima parte o séptima parte del total observado por cada número publicado (Figura 3). Este panorama no es diferente en el $B A P U C P$ en el cual se observaron dos momentos en donde la brecha entre investigadores e investigadoras se amplía (1997-2001 y 2006-2011) y llega a una relación proporcional similar (Figura 4) a la hallada en $A S$ UNMSM.

En la actualidad se identifican dos procesos contrarios: (1) un proceso de crecimiento de la brecha de desigualdad, y que se encuentra relacionado a los nueve últimos números publicados por la revista $A S$ UNMSM y; (2) un proceso de reducción de brechas de desigualdad que se encuentra vinculado a la cantidad de firmas femeninas y masculinas en los seis últimos números publicados por el $B A P U C P$. Estos resultados reafirman y proporcionan evidencia de la disparidad existente al interior de la academia. Asimismo, consideramos que algunos de los factores que impulsan esta situación se encuentran ligados a las políticas editoriales e institucionales, aquellas que no desarrollan ni promueven acciones sostenidas en el tiempo que fomenten la paridad y participación de arqueólogas en cada uno de estos espacios de divulgación académica. 
Tercero, las dos revistas analizadas contienen pequeños destellos de paridad entre años e, incluso, de igualdad y superioridad como en el caso del BA PUCP en 2005. Sin embargo, nos enfrentamos a situaciones poco comunes que pasan a segundo plano cuando identificamos que la participación de firmas femeninas es mínima o nula en otros números, como sucedió en los cinco primeros números de $A S$ UNMSM.

En el apartado de resultados hicimos referencia a la creciente tendencia de colaboración entre investigadoras e investigadores. No obstante, queremos sumar a ello la importanciaqueadquiere la posición en laque seencuentran al momento de participar como colaborador o co-autor, ya que en el sistema de postulación (fondos económicos, becas integrales, concursos docentes, promoción docente, etc.) este orden es puntuado y evaluado. Sobre esta base, el escenario académico arqueológico refleja que las cantidades y porcentajes de autoras entre las tres primeras posiciones, para ambas revistas, desarrolla un proceso que va en aumento. No obstante, las investigadoras femeninas todavía componen una minoría como primeras, segundas y terceras participantes (Figuras 7 y 8).

Aunque aún no se han estudiado cuáles son los factores que generan este sesgo de género, compartimos la idea que la inexistencia de políticas que establezcan la asignación de autorías y la posición de las investigadoras ha contribuido al desarrollo de esta situación (Larivière at al. 2013). En recurrentes ocasiones las arqueólogas han colaborado o trabajado en investigaciones, pero no han sido consideradas a la hora de producir y publicar un artículo. Debemos apuntar, también, la baja participación de mujeres como directoras autónomas de los proyectos de investigación, posición que abre las puertas a generar publicaciones propias debido a la naturaleza de producción de conocimiento en nuestra ciencia. A lo propuesto por Lariviére y sus colegas (2013) debemos sumar la reflexión realizada por Agut (2015), quien sugiere que la ausencia de normas y políticas destinadas a apoyar la situación familiar de las mujeres que desean tener hijos, conduce a que deban elegir entre ello o continuar con su actividad académica porque no encuentran sustento y respaldo para sacar adelante ambos anhelos. Esto ha originado su truncamiento o retraso en el desarrollo profesional, reduciendo sus posibilidades de ocupar altos cargos.

La desigualdad de género en las ciencias, incluida la arqueología, es un problema complejo y multicausal, pero la evidencia también nos sugiere que el tema de procedencia, formación y acceso, juegan un papel importante. Resulta interesante observar las diferencias porcentuales que existen entre las investigadoras peruanas y extranjeras, ya que nos lleva a preguntarnos y reflexionar sobre la actuación de las arqueólogas peruanas, sus posibilidades, medios y condiciones de producción.

En la revista $A S$ UNMSM las autoras peruanas representan el porcentaje más alto de participación con un $66 \%$, frente al $35 \%$ del BA PUCP que las ubica en el segundo lugar de representatividad (Figuras 9 y 10). Si bien, el $B A P U C P$ contiene un mayor número de mujeres participantes en las publicaciones (121), aquellas que provienen de países como Estados Unidos y Argentina ( $42 \%$ y $11 \%$, respectivamente) suman más de la mitad del total de las participantes, situación que nos invita a reflexionar sobre la actuación de las arqueólogas peruanas, así como de las posibilidades y condiciones de producción científica.

Con relación a este tema, es importante resaltar los porcentajes obtenidos tanto de las autoras de universidades peruanas nacionales y privadas. En este punto, identificamos que en la revista AS-UNMSM el $82,69 \%$ de las autoras provienen de universidades nacionales, como la Universidad Nacional Mayor de San Marcos (57,69\%) o la Universidad Nacional San Luis Gonzaga de Ica $(5,76 \%)$ que presentan los porcentajes más altos (Figura 13). La diversidad de las universidades nacionales en esta revista es casi completa, teniendo en cuenta que en el país existen nueve universidades que tienen el programa de arqueología ${ }^{6}$, de las cuales siete se encuentran representadas mediante la participación de investigadoras.

En el caso del BA PUCP la participación de autoras de universidades privadas y nacionales se encuentra casi equiparada con $56 \%$ y $44 \%$ respectivamente. Cabe señalar que la única universidad privada que brinda el programa de arqueología es la Pontificia Universidad Católica del Perú. En cuanto a las universidades nacionales, el BA PUCP es menos diversa en lo que se refiere a la participación de autoras. Dicha participación está liderada por investigadoras de la Universidad Nacional Mayor de San Marcos con 27,77\%, seguida de la Universidad Nacional de Trujillo y la Universidad Nacional San Antonio de Abad del Cusco con 11,11\% y $5,55 \%$, respectivamente.

Es notoria la diferencia de la participación de autoras de universidades nacionales entre la revista $A S$ UNMSM y el BA PUCP. Con respecto a lo anterior, podríamos sugerir que las arqueólogas nacionales encuentran mayor posibilidad y acceso para publicar en $A S$ UNMSM.

\section{Comentarios Finales}

Tanto las investigadoras nacionales como las extranjeras que hacen arqueología en Perú se encuentran todavía subrepresentadas en el ámbito académico. Es decir, existe una infrarrepresentación de las autoras si tenemos en cuenta la producción científica generada por sus pares masculinos. Aunque podríamos hallar alguna respuesta en la tardía incorporación masiva de las mujeres en la arqueología, esta no otorga una respuesta satisfactoria si consideramos el alto porcentaje de arqueólogas formadas en las dos últimas décadas, como 
han demostrados las cifras de SUNEDU e IANAS, presentadas al inicio de esta investigación.

Los resultados aquí mostrados son una radiografía del contexto y las condiciones en las que se forma y ejerce la arqueología en Perú, las cuales son producto de múltiples causas, la mayoría de carácter estructural. Entre ellas podríamos señalar las carencias del sistema educativo nacional, la poca importancia que se le brinda a las ciencias sociales al interior de las entidades públicas dedicadas a la promoción de las ciencias en el país, la inexistencia de fondos públicos que permitan el desarrollo de la arqueología y la ausente creación e impulso de políticas públicas desde los departamentos académicos de las diferentes instituciones universitarias para brindar los medios económicos y sociales que fomenten la participación de las mujeres en la esfera académica.

Asimismo, se observa el impacto de la ausencia de campañas de empoderamiento femenino en su rol como futuras investigadoras y en su incorporación a la carrera misma. Cabe resaltar que si sumamos el número de autoras extranjeras que participan en ambas revistas, estas superan en cantidad a las arqueólogas nacionales. Lo anterior resulta preocupante ante lo que se considera la construcción de la academia peruana, dado que los discursos y temáticas de interés investigativo se encontrarían liderados por instituciones foráneas al Estado peruano, con lo que la inversión y el propósito de las universidades tanto públicas como privadas no estaría desarrollando o logrando sus objetivos.

Finalmente, debemos indicar que los resultados presentados en esta investigación contribuyen a evidenciar con datos empíricos, y por primera vez, la situación actual de las mujeres en la arqueología peruana y emprender un camino de cambio y estudios futuros.

Agradecimientos: Queremos agradecer en primer lugar a las organizadoras de la I Jornada de Estudios de Género realizada en Lima el 12 de octubre del año 2018, por permitirnos participar con nuestra exposición, base importante de este artículo. Así mismo, a quienes, con sus comentarios a nuestra presentación en el mencionado espacio, enriquecieron nuestro trabajo. De igual manera un especial agradecimiento a los y las arqueólogas que fueron revisoras de este texto, ya que sus comentarios y sugerencias han sido un importante aporte en el proceso de producción de este artículo. Finalmente, agradecemos a nuestras familias por apoyarnos en este camino, y a nuestras amigas y amigos que ayudaron en la elaboración de este artículo: Kira Dioses, Diana Reynalte, Enrique Estrada y Henry Tantaleán.

\section{Referencias Citadas}

Agut, L. 2016. Género y Ciencia Avanzada: Análisis Bibliométrico de la Revista Nature desde una Perspectiva de Género. Trabajo Final de Grado de Psicología (PS-1048), Universitat Jaume I, Castello de la Plana.

Alcázar, L. y M. Balarín 2018. Desigualdades en la Academia: Mujeres en las Ciencias Sociales Peruanas. Grupo Sofía, Lima.

Arroyo, P. 2019. Arqueólogas cusqueñas: pasado y presente. Desde el Sur 11 (2):293-303.

Bellelli, C., M. Berón y V. Scheinsohn 1993. Una arqueología de distinto género. Publicar en Antropología y Ciencias Sociales 2 (3):47-61.

Berrocal, M. 2009. Feminismo, teoría y práctica de una arqueología científica. Trabajos de Prehistoria 66 (2):25-43.

Cabrera, M. 2019. Balance y perspectivas de la presencia de mujeres en la carrera de arqueología de la Universidad Nacional de San Cristóbal de Huamanga. Desde el Sur 11 (2):283-291.

Carrión, L. 2008. En homenaje a la Dra. Rosa Fung Pineda (Gran mujer, madre, investigador, maestra y amiga). Arqueología y Vida 2:23-26.

Díaz-Andreu, M. 2013. Epílogo: Ultimas reflexiones y nuevas propuestas. En Historia de la Arqueología en el Perú del Siglo XX, editado por H. Tantaleán, y C. Astuhuamán, pp. 603-616. Instituto Francés de Estudios Andinos/Institute of Andean Research, Lima.

Domínguez, V., J. Vásquez, y M. A. Cordero 2018. Introducción: las mujeres y la arqueología ecuatoriana. En De Arqueología Hablamos las Mujeres: Perspectiva Sobre el Pasado Ecuatoriano, editado por M. A. Cordero, pp. 7-13. Ediciones ULEAM, Manabí.
Gero, J. y M. Conkey (eds.) 1991. Engendering Archaeology. Women and Prehistory. Basil Blackwell, Oxford.

González, J.M. 2009. La participación de las mujeres en la producción científica en ciencia y tecnología en el Perú. Un análisis de los trabajos publicados en ECIPERU, Revista del Encuentro Científico Internacional (2006 - 2009). ECIPERU 6 (2):44-51.

Larivière, V., C. Ni, Y. Gingras, B. Cronin y C.R. Sugimoto 2013. Bibliometrics: global gender disparities in science. Nature 504 (7479):211-213.

Lavallée, D. 2008. Evocación a Rosa Fung Pineda. Arqueología y Vida 2:9-12.

Lavallée, D. 2013. La arqueología francesa en el Perú del siglo XX. En Historia de la Arqueología en el Perú del Siglo XX, editado por H. Tantaleán y C. Astuhuamán, pp. 303-332. Instituto Francés de Estudios Andinos/Institute of Andean Research, Lima.

Novoa, P. 2013. Una aproximación a la obra de Rebeca Carrión Cachot entre 1947 y 1960. En Historia de la Arqueología en el Perú del Siglo XX, editado por H. Tantaleán y C. Astuhuamán, pp. 529-550. Instituto Francés de Estudios Andinos/Institute of Andean Research, Lima.

Olivares, C. (ed.) 1997. Glosario de Términos de Crítica Literaria Femenina El Colegio de México, México DF.

Pacheco, G. 2019. Relaciones de género: mujeres, sanmarquinas y chicheras. Desde el Sur 11 (2):305-316.

Patterson, T. 2013. Prólogo. En Historia de la Arqueología en el Perú del Siglo XX, editado por H. Tantaleán y C. Astuhuamán, pp. 11-6. Instituto Francés de Estudios Andinos/Institute of Andean Research, Lima. 
Pozzi-Escot, D. 2008. Mi reconocimiento a Rosa Fung Pineda. En Arqueología y Vida 2:13-16.

Rossi, A.S. 1965. Women in science, why so few? Science 148 (3674):1196-1202.

Santana, L. 2019. Entre techos de cristal y nichos académicos: estado actual de las mujeres en la arqueología peruana. Desde el Sur 11 (2):261-281.

Silva, J. 2004. Breve semblanza sobre la trayectoria profesional de la Dra. Rosa Fung Pineda. En Quehaceres de la Arqueología Peruana, editado por R. Fung, pp. 15-22. Museo de Arqueología y Antropología de la UNMSM, Lima.

SUNEDU 2019. Estadísticas de Universidades por Programa de Estudio. (21 de enero del 2020). Recuperado de: https:// www.sunedu.gob.pe/sibel (22 de enero del 2020).

Tantaleán, H. 2016. Una Historia de la Arqueología Peruana. Instituto de Estudios Peruanos-Universidad San Francisco de Quito, Lima.
Tantaleán, H. y C. Astuhuamán (eds.) 2013. Historia de la Arqueología en el Perú del siglo XX. Instituto Francés de Estudios Andinos/Institute of Andean Research, Lima.

Tavera, C. 2019. Una mirada feminista a la comunidad arqueológica peruana. Desde el Sur 11 (2):239-260.

Torres, K. y E. Moncayo 2018. Imaginarios, oportunidades y desigualdad de género: de la academia a la práctica arqueológica. En De Arqueología Hablamos las Mujeres: Perspectiva Sobre el Pasado Ecuatoriano, editado por M. Cordero, pp. 163-173. Ediciones ULEAM, Manabí.

Urteaga, F. 2008. Ante una mujer admirable: Rosa Fung Pineda. En Arqueología y Vida 2:17-22.

Vargas, S. (comp.) 2014. Bajo el Radar de Sofia: Oportunidades y Barreras de las Profesionales en el Perú. Instituto de Estudios Peruanos, Lima.

Vázquez-Cupeiro, S. 2015. Ciencia, estereotipos y género: una revisión de los marcos explicativos. Convergencia 22(68):177-202.

\section{Notas}

${ }^{1}$ Dirigido desde agencias gubernamentales como el Programa Nacional de Becas y Crédito Educativo que recientemente ha instaurado la "Beca Mujeres en Ciencia" orientada a estudiantes de educación secundaria de alto rendimiento y que hayan culminado sus estudios en el año de postulación ha dicho incentivo.

${ }^{2}$ Promovido por UNESCO, CONCYTEC, FONDECYT y la Academia Nacional de Ciencia.

${ }^{3}$ El concepto "techo de cristal" "[...] representa las barreras, a menudo "invisibles", que persisten en los ámbitos mencionados y dificultan el acceso de las mujeres a espacios de prestigio, poder y a un mejor salario. Este término tiene su origen en un artículo de Hymowirtz y Scheldart de 1986, publicado en Wall Street Journal (Bastida 2018)" (Santana 2019:263). Las condiciones generadas bajo el "techo de cristal" propician la existencia y consolidación de los "nichos académicos" "[...] los cuales se originan por la tendencia de las mujeres a participar de espacios y temas de investigación específicos, como resultado de estrategias de legitimación, identidad y recurso (Gastiazoro 2013; Helle 2012), que les permiten un mejor desarrollo y búsqueda de comodidad. El nicho académico se puede ejercer y percibir tanto de manera consciente y directa, como inconsciente e indirecta, por las pautas que marcan los espacios laborales y académicos a través del tiempo (Guil 2008)" (Santana 2019:263).
${ }^{4}$ El "sistema sexo/género" se comprende como el "Conjunto de disposiciones por el que una sociedad transforma la sexualidad biológica en productos de la actividad humana y en el cual se satisfacen esas necesidades humanas transformadas" de maneras impuestas por convenciones que son específicas por cada sociedad pero que siempre implican una estratificación por género (Rubi 1986:97, 102, 105)" (Olivares 1997:84). El concepto fue introducido por Gayle Rubin en 1975 con el objetivo de "[...] hablar de un "aparato social sistemático" que produce y reproduce la opresión y subordinación de las mujeres" (Olivares 1997:84).

${ }^{5}$ P.ej., la SUNEDU (2019) registró que durante el 2014 la cantidad de mujeres egresadas de la carrera de arqueología fue de 59 frente a 77 hombres, de un total de siete Escuelas Profesionales de Arqueología a nivel nacional.

${ }^{6}$ Universidad Nacional Mayor de San Marcos, Pontificia Universidad Católica del Perú, Universidad Nacional Federico Villareal, Universidad Nacional de Trujillo, Universidad Nacional Pedro Ruiz Gallo, Universidad Nacional San Cristóbal de Huamanga, Universidad Nacional de San Antonio Abad del Cusco, Universidad Nacional Santiago Antúnez de Mayolo y Universidad Nacional Toribio Rodríguez de Mendoza. 
